\title{
Pre-injury antithrombotic agents predict intracranial hemorrhagic progression, but not worse clinical outcome in severe traumatic brain injury
}

\author{
Teodor Svedung Wettervik ${ }^{1}$ (D) $\cdot$ Samuel Lenell ${ }^{1} \cdot$ Per Enblad $^{1} \cdot$ Anders Lewén $^{1}$
}

Received: 4 January 2021 / Accepted: 16 March 2021 / Published online: 26 March 2021

(C) The Author(s) 2021

\begin{abstract}
Background The incidence of traumatic brain injury (TBI) patients of older age with comorbidities, who are pre-injury treated with antithrombotic agents (antiplatelets and/or anticoagulants), has increased. In this study, our aim was to investigate if preinjury antithrombotic treatment was associated with worse intracranial hemorrhagic/injury progression and clinical outcome in patients with severe TBI.

Methods In this retrospective study, including 844 TBI patients treated at our neurointensive care at Uppsala University Hospital, Sweden, 2008-2018, 159 (19\%) were pre-injury treated with antithrombotic agents. Demography, admission status, radiology, treatment, and outcome variables were evaluated. Significant intracranial hemorrhagic/injury evolution was defined as hemorrhagic progression seen on the second computed tomography $(\mathrm{CT})$, emergency neurosurgery after the initial CT, or death following the initial CT.

Results Patients with pre-injury antithrombotics were significantly older and with a higher Charlson comorbidity index. They were more often injured by falls and more frequently developed acute subdural hematomas. Sixty-eight (8\%) patients were preinjury treated with monotherapy of antiplatelets, 67 (8\%) patients with anticoagulants, and $24(3 \%)$ patients with a combination of antithrombotics. Pre-injury anticoagulants, but not antiplatelets, were independently associated with significant intracranial hemorrhagic/injury evolution in a multiple regression analysis. However, neither anticoagulants nor antiplatelets were associated with mortality and unfavorable outcome in multiple regression analyses.

Conclusions Only anticoagulants were associated with intracranial hemorrhagic/injury progression, but no antithrombotic agent correlated with worse clinical outcome. Management, including early anticoagulant reversal, availability of emergency neurosurgery, and neurointensive care, may be important aspects for reducing the adverse effects of pre-injury antithrombotics.
\end{abstract}

Keywords Anticoagulants $\cdot$ Antiplatelet $\cdot$ Antithrombotics $\cdot$ Clinical outcome $\cdot$ Hemorrhagic progression $\cdot$ Traumatic brain injury

\section{Introduction}

The epidemiology of traumatic brain injury (TBI) is changing. As the population ages, the incidence of old TBI victims with pre-injury comorbidities has increased $[18,19,31,32]$. This implicates new challenges in TBI care, and one particular concern is the pre-injury use of antithrombotic agents.

This article is part of the Topical Collection on Brain trauma

Teodor Svedung Wettervik

teodor.svedung-wettervik@neuro.uu.se

1 Department of Neuroscience, Section of Neurosurgery, Uppsala University, SE-751 85 Uppsala, Sweden
Coagulopathy is a feared complication to TBI and may be further aggravated by pre-injury antithrombotic treatment [20]. However, there is controversy if the negative effect of antiplatelets on platelet function is sufficient to cause increased hemorrhagic progression and to affect clinical outcome after head trauma $[4,7,10,13,14,16,22,26,28,33$, 36-38]. The current guidelines recommend antiplatelet withdrawal in case of post-traumatic intracranial hemorrhage, but there is limited knowledge if and when more active reversal agents, including platelet transfusion or desmopressin, are indicated $[2,12]$. Most studies on pre-injury vitamin $\mathrm{K}$ antagonists treatment demonstrate an increased risk of hemorrhagic progression of intracranial lesions and increased mortality following head trauma $[3,4,6,11,14,26,28,29,36]$, but early vitamin $\mathrm{K}$ antagonists reversal may efficiently counteract 
these adverse effects $[12,15]$. Some recent studies even suggest that pre-injury vitamin $\mathrm{K}$ antagonists no longer impact outcome to a significant extent due to modern management $[18,22]$. Novel oral anticoagulants (NOAC) has increased in incidence and replaced vitamin $\mathrm{K}$ antagonists to some degree [1]. There are concerns that they would favor worse hemorrhagic progression of intracranial lesions after head trauma due to a lack of effective antidotes for most NOACs [12]. However, recent studies demonstrate a lower risk of hemorrhagic progression and better clinical outcome in comparison to patients with pre-injury vitamin $\mathrm{K}$ antagonists in TBI [28, 29]. Furthermore, a subgroup of patients with a severe risk of thromboembolic complications are treated with a combination of antithrombotic agents, such as dual antiplatelets or an antiplatelet together with an anticoagulant. These patients may have an even higher risk of hemorrhagic progression of intracranial lesions and worse clinical outcome [28].

Hence, there are still questions regarding the effect of different pre-injury antithrombotic agents on intracranial hemorrhage progression and clinical outcome after head trauma. Most previous findings are based on patient cohorts from the emergency department including mild TBI cases who did not require neurosurgical interventions. In the current study, we therefore aimed to evaluate the incidence of antithrombotic agents in an updated patient population with severe TBI treated at our tertiary neurointensive care unit, their effect on hemorrhagic progression of intracranial lesions, and the relation to clinical outcome. Our hypotheses were that antithrombotic agents were relatively common, associated with severe hemorrhagic progression, and worse clinical outcome.

\section{Materials and methods}

\section{Patients}

The Department of Neurosurgery at the University Hospital in Uppsala provides neurosurgical care for a central part of Sweden, with a catchment population around 2 million people. Most patients are resuscitated at their local hospitals and then referred to our neurointensive care unit (the most distant local hospital $382 \mathrm{~km}$ away). There were 926 TBI patients aged 15 or older who were treated at our neurointensive care unit between 2008 and 2018 eligible for inclusion in this retrospective study. Seventy-five patients were excluded since they had been treated at another neurointensive care unit before admission to our department if they were discharged to a different catchment area/country with another neurosurgery department. Seven patients were treated twice at our neurointensive care and were therefore registered twice, but we only included data from their first neurointensive care visit. Hence, the final study population included 844 TBI patients.

\section{Management protocol}

Patients were treated in accordance with our standardized intracranial pressure (ICP)- and cerebral perfusion pressureoriented treatment protocol to avoid secondary insults, as previously described in detail $[9,39]$. Unconscious $(\mathrm{GCS} M<6)$ patients were intubated, mechanically ventilated, and received ICP monitoring. Treatment goals were ICP $\leq 20 \mathrm{~mm} \mathrm{Hg}$, cerebral perfusion pressure $\geq 60 \mathrm{~mm} \mathrm{Hg}$, systolic blood pressure $>100 \mathrm{~mm} \mathrm{Hg}$, central venous pressure 0-5 mm Hg, $\mathrm{pO}_{2}$ $>12 \mathrm{kPa}$, arterial glucose $5-10 \mathrm{mmol} / \mathrm{L}(\mathrm{mM})$, hemoglobin > $100 \mathrm{~g} / \mathrm{L}$, electrolytes within normal ranges, normovolemia, and body temperature $<38^{\circ} \mathrm{C}$. Patients were initially mildly hyperventilated $(4.0-4.5 \mathrm{kPa})$ and normoventilated as soon as ICP allowed.

For patients with pre-injury antithrombotic agent treatment, the antithrombotic agent was withdrawn following TBI. Antiplatelets were generally only withdrawn but was occasionally reversed with thrombocytes and/or desmopressin. Vitamin $\mathrm{K}$ antagonists were reversed with vitamin $\mathrm{K}$ and prothrombin complex concentrate. NOAC was withdrawn and sometimes treated with cyklokapron and/or prothrombin complex concentrate.

\section{Data acquisition and analysis}

Demographic, admission, and treatment variables were collected from the Uppsala TBI register [24]. The extent of comorbidities was evaluated according to the Charlson comorbidity index [34]. Routine blood and coagulation status including hemoglobin, platelets, PK-INR, and APTT at admission were evaluated. The testing was done at the accredited laboratory of the Department of Clinical Chemistry at Uppsala University Hospital.

Computed tomography (CT) scans of the brain were evaluated according to the Marshall classification [21]. The size of intracranial hemorrhages was evaluated and compared on the first two CT scans. Hemorrhage progression of intracranial lesions was defined similarly to Shin et al. [29], as an increase on the second CT in (1) epidural hematoma (EDH) or acute subdural hematoma (ASDH) width with more than $2 \mathrm{~mm}$, (2) traumatic subarachnoid hemorrhage (tSAH) by visual inspection, (3) intraventricular hemorrhage (IVH) with more than $2 \mathrm{~mm}$ in lateral width, and/or (4) cerebral contusions with more than $6 \mathrm{~mL}$ or $33 \%$. The contusion volume was calculated according to the $\mathrm{ABC} / 2$ formula [17]. However, some patients received emergency neurosurgery immediately after the first CT, and some patients had large intracranial hemorrhages and were in such a poor clinical condition that they were not considered to benefit from surgery and developed total brain death before a second CT was done. To take into account these different clinical trajectories of hemorrhage/injury evolution, we divided the patients into four groups: (1) stable 
intracranial hemorrhages on follow-up CT, (2) progression of intracranial hemorrhages as defined above on follow-up CT, (3) immediate intracranial surgery after the first CT, and (4) total brain infarction (brain death) confirmed before a second CT. For statistical purposes, we also dichotomized these groups into stable intracranial lesions at follow-up CT (group 1) and significant intracranial hemorrhage/injury evolution (groups 2, 3, and 4).

Clinical outcome was assessed by specially trained personnel with structured telephone interviews at 6 months postinjury using the Extended Glasgow Outcome Scale (GOSE), containing eight categories of global outcome, from death to upper good recovery $[24,35,40]$. The interviews were held with the patients if they had recovered sufficiently, otherwise, with their next of kin.

\section{Statistical analysis}

Demography, admission status, coagulation status, treatments, and clinical outcome were described as median (interquartile range) or number (proportion). The Mann-Whitney $U$-test and Pearson's chi-square analysis were used for statistical comparisons between patients that were pre-injury treated with ATs and those who did not receive such treatment. Missing values were rare, and those were excluded from the analyses.

Differences in hemorrhagic/injury progression of intracranial lesions (stable, progression, emergency surgery, or total brain infarction) in relation to pre-injury antithrombotic agents were evaluated with Pearson's Chi-square analysis. A similar sub-analysis was done for different types of antithrombotic agents (antiplatelets, anticoagulants, and multiple/a combination of antithrombotic agents). Multiple logistic regression analyses were done to evaluate the risk of significant intracranial hemorrhage/injury progression (groups 2, 3, and 4, i.e., progression of lesions on follow-up CT, immediate neurosurgery, or total brain infarction) using only pre-injury variables age, Charlson comorbidity index, and antithrombotic agents in combination with mechanism of injury as explanatory variables. A similar multiple logistic regression analysis was done with the various antithrombotic subtypes instead of antithrombotic agents (as one group) as explanatory variables for significant intracranial hemorrhage progression. In addition to hemorrhage evolution, brain edema is another contributing cause for emergency neurosurgery. We therefore evaluated if exclusion of those patients with the supposedly worst early brain edema development (defined as those operated with primary DC and those with immediate brain death after the first CT) had any impact upon the results.

The relation between antithrombotic agents and mortality and favorable clinical outcome at 6 months was evaluated with Pearson's chi-square test. Multiple logistic regression analyses were also performed for mortality and favorable outcome, respectively, as dependent variables and pre-injury variables (age,
Charlson comorbidity index, and antithrombotic agents) in combination with mechanism of injury as explanatory variables. A similar multiple logistic regression analysis was done using the antithrombotic subtypes instead of antithrombotic agents (as one group) as explanatory variables for mortality and favorable clinical outcome at 6 months. Similar regression analyses of clinical outcome with the traditional IMPACT core variables [30] as explanatory variables were also performed. A $p$-value $<0.05$ was considered statistically significant.

\section{Results}

\section{Demography, admission status, and treatments}

Descriptive clinical data for the entire TBI patient population is described in Table 1. There were 844 TBI patients included in the study, of which $159(19 \%)$ patients were pre-injury treated with antithrombotic agents, whereas 685 (81\%) patients were not on such agents. The differences in demography, admission status, and treatments between the two groups are also described in Table 1.

\section{Antithrombotics - types of agents, indication, coagulation status, and reversal treatment}

The various types of pre-injury antithrombotic agents and their indications are described in Fig. 1. Eighty-nine (56\%) of the patients with antithrombotic agents were pre-injury treated with antiplatelets. Sixty-three (40\%) patients had aspirin as monotherapy, 5 (3\%) patients had clopidogrel as monotherapy, and 21 (13\%) patients had an antithrombotic combination of an antiplatelet together with another antithrombotic agent (antiplatelet or anticoagulant). Eighty-two (52\%) of the 159 patients with antithrombotic agents were pre-injury treated with anticoagulants. Fifty-seven (36\%) patients had a vitamin $\mathrm{K}$ antagonist as monotherapy, $6(4 \%)$ patients had NOAC as monotherapy, 5 (3\%) patients had low-molecular weight heparin as monotherapy, and $15(9 \%)$ had an antithrombotic combination of an anticoagulant together with another antithrombotic agent (antiplatelet or anticoagulant). There were in total $24(15 \%)$ patients with a combination of pre-injury antithrombotic agent. Ten $(6 \%)$ patients received dual antiplatelets (aspirin $+\mathrm{P}_{2} \mathrm{Y}_{12}$-inhibitor), 12 (8\%) patients received a combination of antiplatelet and anticoagulant ( 9 patients with aspirin + vitamin $\mathrm{K}$ antagonist, 2 patients with aspirin + low-molecular weight heparin, and 1 patient with clopidogrel + heparin), and $2(1 \%)$ patients received dual anticoagulants (1 patient with vitamin $\mathrm{K}$ antagonist + low-molecular weight heparin and 1 patient with lowmolecular weight heparin + fondaparinux/Arixtra). The reversal management of these different antithrombotic agents is described in Table 2. 


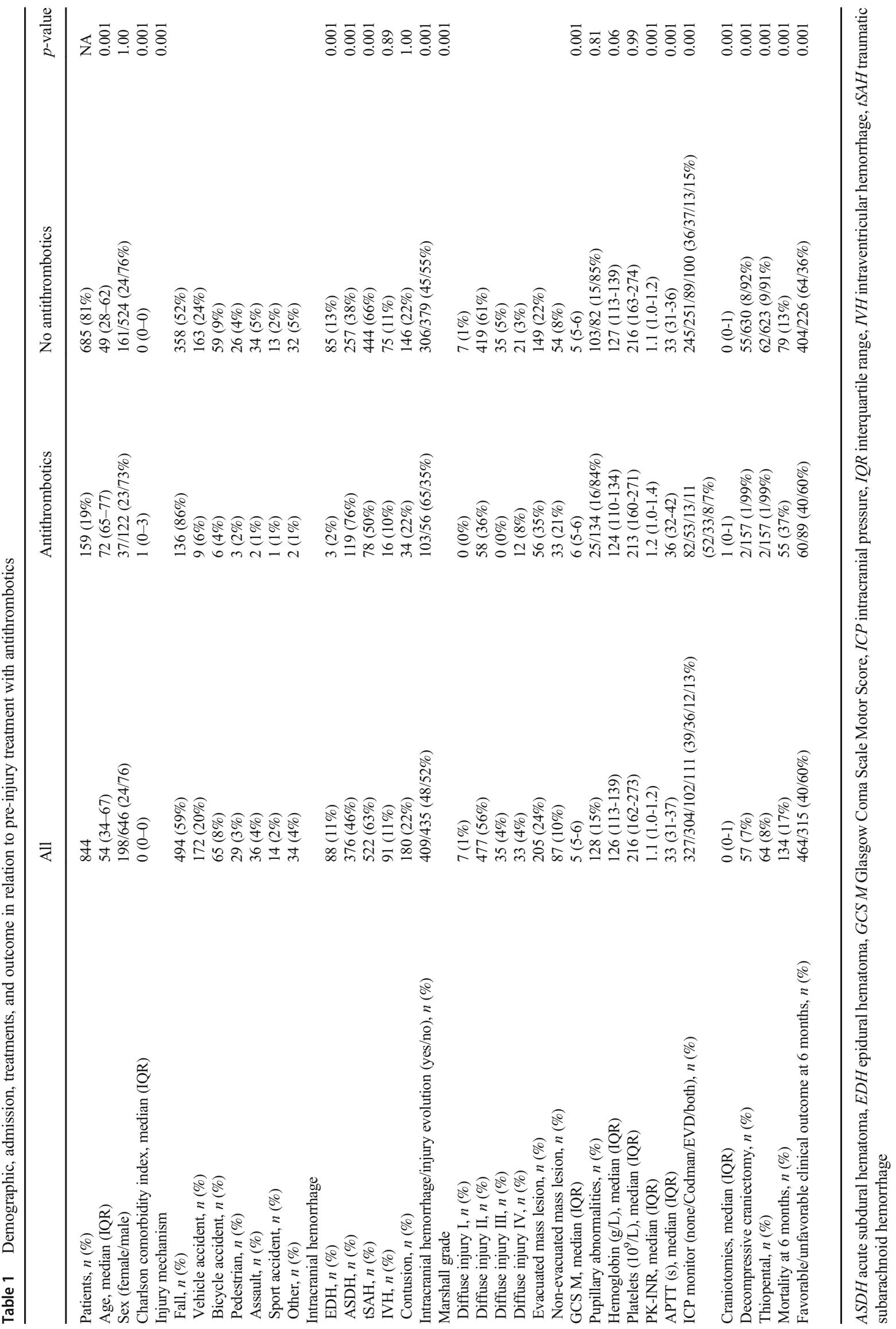


Fig. 1 Types of antithrombotic agents and indications for treatment. AF, atrial fibrillation; $\mathrm{AT}$, antithrombotic; CAD, coronary artery disease; LMWH, low-molecular weight heparin; NOAC, novel oral anticoagulant; VKA, vitamin $\mathrm{K}$ antagonist; VTE, venous thromboembolism a

Antithrombtic agents - types (\%)

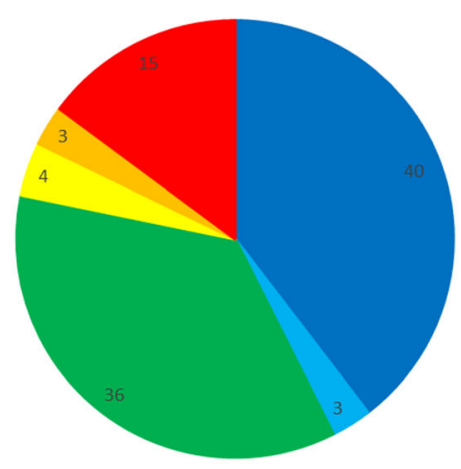

aspirin Clopidogrel $\square$ VKA NOAC $\square$ LMWH Double AT

b

Antithrombotic agents - indication (\%)

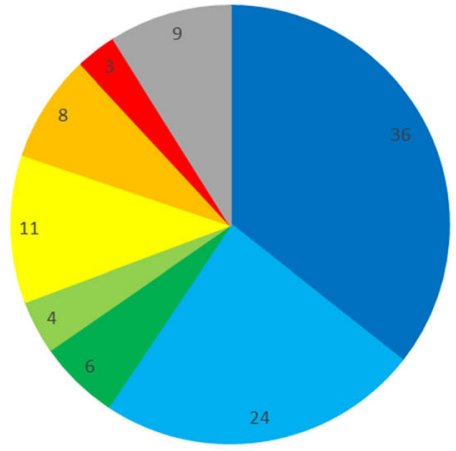

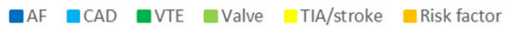

Coagulation disorder Unspecified
Those with pre-injury antithrombotic agents had significantly higher PK-INR (median 1.2 IQR 1.0-1.4 vs. 1.1 IQR 1.0-1.2, pvalue 0.001 ) and higher APTT (median 36 IQR $32-41$ vs. 33 IQR 31-36, $p$-value $=0.001$ ) at neurointensive care admission. There was no difference in hemoglobin (median 124 IQR 110 134 vs. 127 IQR $113-139, p$-value $=0.06$ ) or platelets (median 213 IQR $160-271$ vs. 216 IQR 163-274, $p$-value $=0.99)$.

\section{Antithrombotic agents-relation to post-traumatic intracranial hemorrhage/injury evolution}

Patients with pre-injury antithrombotic agents were significantly less likely to have a hemorrhage that was stable at follow-up CT than those without pre-injury antithrombotic treatment (35\%, vs. $55 \%, p$-value $=0.001)$. In a sub-analysis, the risk of having a significant post-traumatic intracranial hemorrhage/injury evolution was independently associated with pre-injury treatment with anticoagulants (Fig. 2 and Table 3). Antiplatelets or a combination of two antithrombotic agents were not independent risk factors for significant post-traumatic intracranial hemorrhage evolution. Lower age and a vehicle accident rather than falls as the mechanism of injury were independently associated with a lower risk of significant post-traumatic intracranial hemorrhage/injury evolution. Similar associations in the regressions were found if those with primary DC $(n=29)$ and those who developed early brain death after the first $\mathrm{CT}(n=15)$ were excluded from the analyses. The second CT was in median performed $10 \mathrm{~h}$ (IQR 620) after the first CT.

\section{Antithrombotics - relation to mortality and favorable clinical outcome}

Pre-injury antithrombotic agents were significantly associated with increased mortality $(37 \%$ vs. $13 \%, p$-value $=0.001)$ and decreased rate of favorable clinical outcome ( $40 \%$ vs. $64 \%, p$ value $=0.001)$ at 6 months in univariate analyses (Table 1$)$. However, in a multiple logistic regression analysis, only higher age and higher Charlson comorbidity index were associated with higher mortality and decreased rate of favorable clinical outcome, whereas pre-injury antithrombotic agents were not (Table 4). Similarly, a sub-analysis of antiplatelets, anticoagulants, and a combination of antithrombotic agents in 
Table 2 Antithrombotic agents and reversal management

\begin{tabular}{|c|c|c|c|c|}
\hline Antithrombotic regime & Antithrombotic agent & Patients, $n$ & Reversal & Patients, $n(\%)$ \\
\hline \multirow[t]{5}{*}{ Antiplatelet } & \multirow[t]{3}{*}{ Aspirin } & \multirow[t]{3}{*}{63} & Withdrawal & $58(92 \%)$ \\
\hline & & & Platelet transfusion and desmopressin & $4(6 \%)$ \\
\hline & & & Protein complex concentration & $1(2 \%)$ \\
\hline & \multirow[t]{2}{*}{ Clopidogrel } & \multirow[t]{2}{*}{5} & Withdrawal & $4(80 \%)$ \\
\hline & & & Platelet transfusion and desmopressin & $1(20 \%)$ \\
\hline \multirow[t]{8}{*}{ Anticoagulants } & \multirow[t]{2}{*}{ Vitamin $\mathrm{K}$ antagonist } & \multirow[t]{2}{*}{57} & Withdrawal & $1(2 \%)$ \\
\hline & & & Vitamin $\mathrm{K}+$ protein complex concentration & $56(98 \%)$ \\
\hline & \multirow[t]{4}{*}{ NOAC } & \multirow[t]{4}{*}{6} & Withdrawal & $1(17 \%)$ \\
\hline & & & Praxbind & $1(17 \%)$ \\
\hline & & & Tranexamic acid + protein complex concentration & $1(17 \%)$ \\
\hline & & & Vitamin $\mathrm{K}+$ protein complex concentration & $3(50 \%)$ \\
\hline & \multirow[t]{2}{*}{ LMWH } & \multirow[t]{2}{*}{5} & Withdrawal & $4(80 \%)$ \\
\hline & & & Plasma transfusion & $1(20 \%)$ \\
\hline \multirow[t]{6}{*}{ Antithrombotic combination } & \multirow[t]{2}{*}{ Dual antiplatelets } & \multirow[t]{2}{*}{10} & Withdrawal & $5(50 \%)$ \\
\hline & & & Platelet transfusion and desmopressin & $5(50 \%)$ \\
\hline & Aspirin + vitamin $\mathrm{K}$ antagonist & 9 & Vitamin $\mathrm{K}+$ protein complex concentration & $9(100 \%)$ \\
\hline & Aspirin + LMWH & 2 & Withdrawal & $2(100 \%)$ \\
\hline & Clopidogrel + heparin & 1 & Withdrawal & $1(100 \%)$ \\
\hline & Dual anticoagulants & 2 & Vitamin $\mathrm{K}+$ protein complex concentration/plasma & $2(100 \%)$ \\
\hline
\end{tabular}

$L M W H$ low-molecular weight heparin, $N O A C$ novel oral anticoagulant

the same regression instead of antithrombotics (as one group) did not reveal any significant association with mortality or favorable clinical outcome. Similarly, pre-injury antithrombotic agents were not independently associated with mortality or favorable clinical outcome in regressions including the IMPACT core variables (Supplementary, Appendix A).

\section{Discussion}

In the current study including 844 patients with severe TBI treated at our neurointensive care unit between 2008 and 2018, we found that those with pre-injury antithrombotic agents, particularly anticoagulants but not pre-injury antiplatelets, were more likely to suffer from significant post-traumatic intracranial hemorrhage evolution. The rate of anticoagulant reversal was high, and the patients often required emergency neurosurgery. Interestingly, neither anticoagulants nor antiplatelets were independently associated with increased mortality or decreased rate of favorable clinical outcome. The main conclusion is that caution is needed due to the risk of significant hemorrhagic progression of intracranial lesions in patients with pre-injury anticoagulants, but favorable outcome may be achieved. Early anticoagulant reversal, emergency neurosurgery, and neurointensive care may be important aspects to counteract the adverse effects of antithrombotic agents in case of TBI.

\section{Antithrombotics and post-traumatic intracranial hemorrhagic progression}

Traumatic forces to the head pose a risk of neurovascular disruption with development of intracranial hemorrhages. This risk may increase due to trauma-induced coagulopathy and preinjury treatment with antithrombotic agents [20]. As the general population is aging, the incidence of TBI patients who are older has comorbidities, and pre-injury antithrombotic agents is also rising $[1,18,19]$. There is hence a need for a better understanding of post-traumatic intracranial hemorrhage evolution for patients treated with pre-injury antithrombotic agents and for specific antithrombotic types, to better appreciate the risk for severe deterioration and clinical outcome.

Although antithrombotic agents may induce a worsening of primary hemostasis and/or coagulation, the risk of severe antithrombotic agent-induced coagulopathy and significant hemorrhage progression in general $[5,25]$ and following head trauma specifically $[7,10,16,22,26,28,38]$ remain controversial. In a meta-analysis based on 20,000 patients, pre-injury antiplatelets were associated with an increased risk of development of an intracranial hemorrhage after head trauma [38], particularly following clopidogrel $[10,16]$. However, these studies mainly evaluated the relation between pre-injury antiplatelets in mild TBI in the emergency department setting with exclusion of patients who required emergency neurosurgery [10]. More recent studies have 


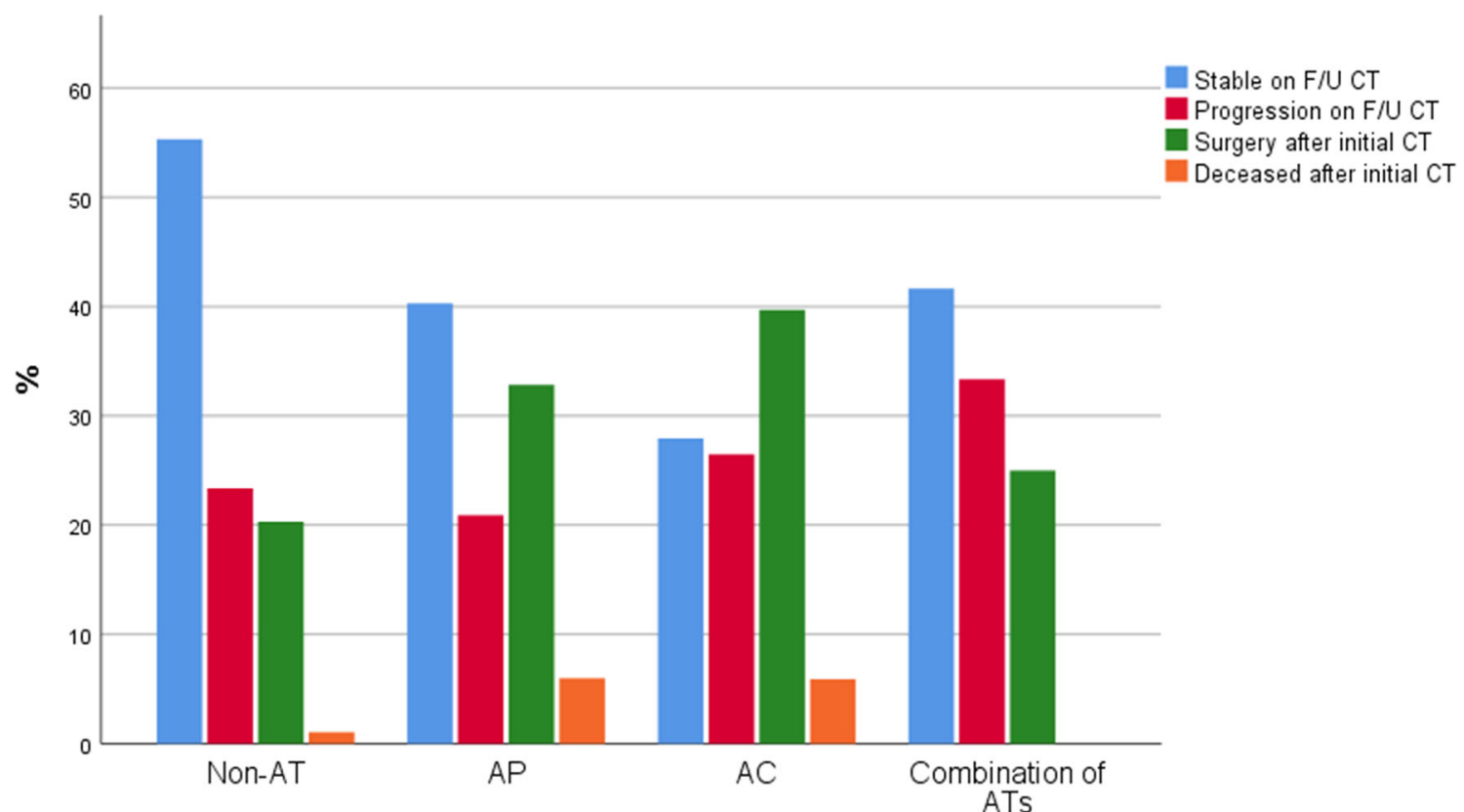

Fig. 2 Antithrombotic agents in relation to hemorrhagic progression, the need for immediate surgery, and death. The figure demonstrates the relation among antithrombotic agents and intracranial hemorrhage progression, defined as either stable on F/U CT (a.k.a. group 1), significant progression on $\mathrm{F} / \mathrm{U} \mathrm{CT}$ (group 2), emergency neurosurgery after initial CT (group 3), and deceased after the initial CT (group 4). In the non-AT group, the number of patients in group $1 / 2 / 3 / 4$ was $379 / 160 / 139 / 7$ patients. In the

AP group, the number of patients in group $1 / 2 / 3 / 4$ was $27 / 14 / 22 / 4$. In the AC group, the number of patients in group $1 / 2 / 3 / 4$ was $19 / 18 / 27 / 4$. In the combination of ATs group, the number of patients in group 1/2/3/4 was 10/8/6/0. Eighty-six (43\%) of 200 patients with significant hemorrhage progression on F/U CT (group 2) required a craniotomy for hematoma evacuation later. AC, anticoagulant; AP, antiplatelet; AT, antithrombotic agent; F/U, follow-up; $\mathrm{CT}$, computed tomography

found no association between antiplatelets and hemorrhagic progression of post-traumatic lesions [7, 13, 28, 36], although Mathieu et al. found in a volumetric analysis that there was a

small but significant increase in hemorrhage progression in cases with pre-injury antiplatelet treatment in the CENTER-TBI cohort, but it did not correlate with worse clinical outcome [22].

Table 3 Antithrombotic agents and the risk of significant intracranial hemorrhage/injury evolution (progression, immediate surgery, and total brain infarction) - a multiple logistic regression analysis

\begin{tabular}{|c|c|c|c|c|}
\hline \multirow[t]{2}{*}{ Variables } & \multicolumn{2}{|c|}{$\begin{array}{l}\text { Regression } 1 \text {-significant hemor- } \\
\text { rhage }\end{array}$} & \multicolumn{2}{|c|}{$\begin{array}{l}\text { Regression 2-significant hemor- } \\
\text { rhage }\end{array}$} \\
\hline & OR $(95 \% \mathrm{CI})$ & $p$-value & OR $(95 \% \mathrm{CI})$ & $p$-value \\
\hline Age & $1.02(1.01-1.03)$ & 0.001 & $1.02(1.01-1.03)$ & 0.001 \\
\hline Charlson comorbidity index & $0.99(0.86-1.13)$ & 0.84 & $1.00(0.87-1.15)$ & 0.97 \\
\hline Antithrombotic agent (yes) & $1.27(0.81-1.99)$ & 0.29 & NA & NA \\
\hline Antiplatelet (yes) & NA & NA & $0.98(0.56-1.73)$ & 0.94 \\
\hline Anticoagulant (yes) & NA & NA & $1.94(1.08-3.47)$ & 0.03 \\
\hline Combination of antithrombotics (yes) & NA & NA & $0.61(0.23-1.65)$ & 0.33 \\
\hline Injury mechanism (fall-reference) & & 0.01 & & 0.004 \\
\hline Vehicle accident & $0.43(0.29-0.65)$ & 0.001 & $0.42(0.28-0.63)$ & 0.001 \\
\hline Bicycle accident & $0.64(0.38-1.10)$ & 0.11 & $0.65(0.38-1.11)$ & 0.11 \\
\hline Pedestrian & $0.78(0.36-1.68)$ & 0.78 & $0.77(0.36-1.67)$ & 0.51 \\
\hline Assault & $0.57(0.27-1.20)$ & 0.14 & $0.55(0.26-1.15)$ & 0.11 \\
\hline Sport accident & $0.85(0.28-2.57)$ & 0.77 & $0.82(0.27-2.49)$ & 0.72 \\
\hline Other & $0.96(0.47-1.95)$ & 0.90 & $0.94(0.46-1.92)$ & 0.07 \\
\hline
\end{tabular}

The multiple logistic regression analyses describe the explanatory variables for significant intracranial hemorrhage/injury progression (defined as significant hemorrhage progression on follow-up CT, immediate hematoma evacuation after the first CT, or immediate death after the first CT) in contrast to stable intracranial hemorrhage on follow-up CT. Pre-injury treatment with antithrombotic agents was grouped as one entity in regression 1, whereas different antithrombotic subtypes (antiplatelets, anticoagulants, and having a combination of antithrombotics) were analyzed in regression 2. $C I$ confidence interval, $C T$ computed tomography, $N A$ not applicable

Bold and italics indicate statistical significance 
Table 4 Antithrombotic agents in relation to mortality and favorable clinical outcome - a multiple logistic regression analysis

\begin{tabular}{|c|c|c|c|c|}
\hline \multirow[t]{2}{*}{ Variables } & \multicolumn{2}{|c|}{ Regression 1 -mortality } & \multicolumn{2}{|c|}{ Regression 2-mortality } \\
\hline & OR $(95 \% \mathrm{CI})$ & $p$-value & OR $(95 \% \mathrm{CI})$ & $p$-value \\
\hline Age & $1.04(1.03-1.06)$ & 0.001 & $1.04(1.03-1.06)$ & 0.001 \\
\hline Charlson comorbidity index & $1.39(1.19-1.63)$ & 0.001 & $1.42(1.21-1.67)$ & 0.001 \\
\hline Antithrombotic agent (yes) & $1.20(0.72-2.02)$ & 0.49 & NA & NA \\
\hline Antiplatelet (yes) & NA & NA & $0.87(0.45-1.71)$ & 0.69 \\
\hline Anticoagulant (yes) & NA & NA & $1.37(0.75-2.53)$ & 0.31 \\
\hline Combination of antithrombotics (yes) & NA & NA & $0.88(0.29-2.66)$ & 0.83 \\
\hline Mechanism of injury ( 7 categories) & NA & 0.69 & NA & 0.70 \\
\hline \multirow[t]{2}{*}{ Variables } & \multicolumn{2}{|c|}{ Regression 1-favorable outcome } & \multicolumn{2}{|c|}{ Regression 2 -favorable outcome } \\
\hline & OR $(95 \% \mathrm{CI})$ & $p$-value & OR (95\% CI) & $p$-value \\
\hline Age & $0.97(0.96-0.98)$ & 0.001 & $0.97(0.96-0.98)$ & 0.001 \\
\hline Charlson comorbidity index & $0.84(0.72-0.98)$ & 0.02 & $0.81(0.69-0.95)$ & 0.01 \\
\hline Antithrombotic agent (yes) & $1.01(0.64-1.60)$ & 0.96 & NA & NA \\
\hline Antiplatelet (yes) & NA & NA & $1.36(0.75-2.46)$ & 0.31 \\
\hline Anticoagulant (yes) & NA & NA & $0.91(0.51-1.62)$ & 0.74 \\
\hline Combination of antithrombotics (yes) & NA & NA & $1.42(0.51-3.95)$ & 0.50 \\
\hline Mechanism of injury (7 categories) & NA & 0.44 & NA & 0.45 \\
\hline
\end{tabular}

The multiple logistic regression analyses describe the explanatory variables for mortality and favorable outcome, respectively. Pre-injury treatment with antithrombotic agents was grouped as one entity in regression 1, whereas different antithrombotic subtypes (antiplatelets, anticoagulants, and having a combination of antithrombotics) were analyzed in regression 2. CI confidence interval, $N A$ not applicable

Bold and italics indicate statistical significance

In the current study, we investigated patients with severe TBI admitted to the neurointensive care and found no significant association between antiplatelets and significant intracranial hemorrhage evolution. However, aspirin was the predominant antiplatelet, and only 5 patients received monotherapy with clopidogrel, why no further sub-analysis was done. It is possible that low-dose aspirin has a more limited impact on intracranial hemorrhage progression after head trauma, which could explain why antiplatelets did not correlate with worse intracranial hemorrhage evolution in our study.

However, previous studies have found clear evidence of intracranial hemorrhage progression following head trauma for patients who were pre-injury treated with vitamin $\mathrm{K}$ antagonists $[6,11,28,36]$. Fabbri et al. did not find such an association [11], but they did not include those cases who required emergency neurosurgery, which could have excluded several cases with vitamin $\mathrm{K}$ antagonists. Consistent with the most previous studies, we found that pre-injury anticoagulant treatment was independently associated with an increased risk of significant hemorrhage evolution in severe TBI cases admitted to the NIC. Some recent studies have found a lower rate of severe intracranial hemorrhages with NOAC as compared to vitamin $\mathrm{K}$ antagonists [13, 28, 29]. However, only 6 patients were pre-injury treated with NOAC as monotherapy, why no further sub-analysis was performed.

Previous studies have reported an increased risk of severe intracranial hemorrhage progression in TBI for patients with a combination of antithrombotic agents [28]. In our study, the patients with a combination of antithrombotic agents had a trend towards increased hemorrhagic progression, but it did not reach statistical significance. This could be explained by the limited number of patients $(n=24)$ with such antithrombotic regimens and the heterogeneity in antithrombotic combinations in the current study.

In addition, we found that higher age was independently associated with significant hemorrhage evolution. Dunham et al. [7] found in a previous study including 198 TBI patients, in which most cases were mild to moderate, that pre-injury brain atrophy rather than antithrombotic agents predicted intracranial hemorrhage progression. It is likely that higher age with a corresponding brain atrophy may favor hemorrhage progression due to higher intracranial compliance with less hemorrhage tamponade. However, the lack of association between preinjury antithrombotic agents and intracranial hemorrhage progression in their study could be explained by a smaller patient population.

\section{Antithrombotic agents and clinical outcome}

The effect of pre-injury antithrombotic treatment on clinical outcome following TBI remains controversial $[6,7,10,13,15,18$, 28, 36, 38]. Pre-injury antiplatelets are not associated with a higher mortality or worse clinical outcome in most studies [4, $14,33,36]$, although others have demonstrated an association with mortality [23]. However, the latter study did not adjust for confounding variables including age and comorbidities. Consistent with previous findings, we only found a significant association between antiplatelets and higher mortality and a decreased rate of favorable outcome in the univariate analysis, but not after adjustment for age and comorbidities. Active antiplatelet reversal was uncommon in our study, and less than $10 \%$ were treated with platelet transfusion/desmopressin, while antiplatelet 
withdrawal alone was the predominant management. Since preinjury antiplatelet treatment was not associated with a worse intracranial hemorrhage evolution despite a low rate of reversal treatments, this supports that antiplatelet withdrawal is usually sufficient. However, interestingly, Barletta et al. found in a recent study that desmopressin treatment was significantly associated with lower intracranial hemorrhage progression after head trauma for patients with pre-injury antiplatelets, indicating a small benefit of desmopressin for these patients [2]. Future trials are needed to better determine when antiplatelet withdrawal is sufficient and if or when platelet transfusion and desmopressin are indicated. Altogether, these findings indicate that pre-injury antiplatelets are safe and do not generally have a significant impact on intracranial hemorrhage evolution and clinical outcome. However, the validity of these findings might be limited to low-dose aspirin, considering the low incidence of other antiplatelets.

Vitamin K antagonists are associated with increased mortality and unfavorable clinical outcome in many TBI studies $[4,11,14$, $28,29,36]$, but we and others have found no such associations $[18,22]$. In the current study, anticoagulants were associated with a higher mortality and a decreased rate of favorable clinical outcome in the univariate analysis, but not after adjustment for age, comorbidities, and mechanism of injury. It has clearly been demonstrated that early reversal of vitamin $\mathrm{K}$ antagonists reduces hemorrhage progression and mortality [15] and it is possible that early reversal, in addition to the availability of emergency neurosurgery, may compensate for the increased risk of hemorrhagic progression. Some recent studies indicate that NOACs are associated with better clinical outcome than vitamin $\mathrm{K}$ antagonists after head trauma [28, 29]; however, due to the limited number of patients with pre-injury NOAC in the current study, we could not proceed with such a sub-analysis. Altogether, anticoagulants were independently associated with significant intracranial hemorrhage evolution, but not with worse clinical outcome. It is likely that early reversal of anticoagulants, emergency neurosurgery, and neurointensive care may compensate for the adverse effects of antithrombotic agents.

Furthermore, previous studies have found a worse clinical outcome for patients with a combination of antithrombotic agents [28]. This was not evident in the current study, but as outlined above, this could be explained by the heterogeneity of antithrombotic types and the limited number of patients with combined antithrombotic agents in the current study.

In addition, the role of tranexamic acid after TBI has gained interest, but the results from the CRASH-3 study are not in clear favor for early tranexamic acid treatment since only a sub-group of patients showed a modest decrease in mortality and other studies have followed where authors report no effect or increased mortality after tranexamic acid treatment in severe TBI $[8,27]$. However, it is not ruled out that such treatment may be particularly important for a subgroup with preinjury increased coagulopathy.

\section{Limitations}

First, the patients included in the study were selected for admission to our tertiary neurointensive care unit if a favorable prognosis was considered possible. It is possible that some patients with antithrombotic agent-induced coagulopathy were excluded from neurointensive care admission and hence to the current study due to severe intracranial hemorrhages with a poor prognosis. The validity of our findings is therefore limited to those considered to benefit from neurointensive care. Second, although we included a significant number of patients $(n=844)$ over a wide time interval of 11 years, there was only a limited number of patients with clopidogrel and NOAC. This prohibited us from proceeding with further sub-analyses on their association with intracranial hemorrhage progression and clinical outcome. This also limits the validity of our findings to mostly aspirin and vitamin $\mathrm{K}$ antagonists. Third, there was great variation in the treatment of pre-injury antiplatelet treatment. It is possible that more aggressive reversal strategies were employed in cases with more severe intracranial hemorrhage evolution due to the concurrent coagulopathy or more severe traumatic forces to the head. Fourth, due to the large amount of radiological images evaluated in the current study, the analyses of hemorrhagic progression were only performed by one of the authors (TSW) as it was very time-consuming. The reliability of the radiological assessments is therefore limited to some extent. Fifth, our definition of intracranial hemorrhage evolution was based on a clinical point of view of significant hemorrhage progression, but it is possible that also antiplatelets would have been associated with a slight increase in clinically silent intracranial hemorrhage progressions. Sixth, groups 3 and 4 (emergency neurosurgery and early total brain infarction after the first CT, respectively) could in some cases represent progression of brain edema/injury rather than hemorrhage progression. We took this into account to some degree by evaluating if excluding those patients with presumed severe brain edema development (those operated with primary DC and those in group 4) from the regressions in Table 3 had any impact upon the results, but found no such effect.

\section{Conclusions}

Antithrombotic agents are nowadays common, and almost onefifth of the patients admitted for severe traumatic brain injury to our neurointensive care unit were pre-injury treated with such agents. In the majority of the patients with pre-injury antiplatelets, their medication was withdrawn but not treated with reversal agents, whereas almost all patients with vitamin $\mathrm{K}$ antagonists were treated with reversal agents. Those with pre-injury anticoagulants, but not those with pre-injury antiplatelets, were at higher risk for a more severe intracranial hemorrhage evolution. Patients with pre-injury antithrombotic agents had a higher risk for mortality and a decreased rate of favorable outcome compared to 
those without antithrombotic agents, but not in multiple regression analyses, as the former association was rather explained by higher age and more extensive comorbidities. This highlights that patients with severe traumatic brain injury who are pre-injury treated with antithrombotic agents, particularly anticoagulants, are at increased risk of severe intracranial hemorrhage evolution, but management, including anticoagulant reversal, emergency neurosurgery, and neurointensive care, may be important to achieve favorable outcome in these patients.

Supplementary Information The online version contains supplementary material available at https://doi.org/10.1007/s00701-021-04816-0.

Acknowledgements We express our gratitude to the personnel at the neurointensive care unit, Uppsala University Hospital, for meticulous patient care and gathering of outcome data.

Funding Open access funding provided by Uppsala University. The study was funded by the Department of Neuroscience, Uppsala University.

\section{Declarations}

Ethics approval All procedures performed in the studies involving humans were in accordance with the ethical standards of the national research committee and with the 1964 Helsinki declaration and its later amendments. The study was approved by Uppsala University Regional Ethical Board (Dnr 2010/138 and Dnr 2010/138/1) and the Swedish Ethical Review Authority (2020-05462).

Informed consent Informed consent was obtained during NIC from the next of kin or by the patient after recovery at follow-up.

Conflict of interest The authors declare no competing interests.

Open Access This article is licensed under a Creative Commons Attribution 4.0 International License, which permits use, sharing, adaptation, distribution and reproduction in any medium or format, as long as you give appropriate credit to the original author(s) and the source, provide a link to the Creative Commons licence, and indicate if changes were made. The images or other third party material in this article are included in the article's Creative Commons licence, unless indicated otherwise in a credit line to the material. If material is not included in the article's Creative Commons licence and your intended use is not permitted by statutory regulation or exceeds the permitted use, you will need to obtain permission directly from the copyright holder. To view a copy of this licence, visit http://creativecommons.org/licenses/by/4.0/.

\section{References}

1. Adelborg K, Grove EL, Sundbøll J, Laursen M, Schmidt M (2016) Sixteen-year nationwide trends in antithrombotic drug use in Denmark and its correlation with landmark studies. Heart 102: 1883-1889. https://doi.org/10.1136/heartjnl-2016-309402
2. Barletta JF, Abdul-Rahman D, Hall ST, Mangram AJ, Dzandu JK, Frontera JA, Zach V (2020) The role of desmopressin on hematoma expansion in patients with mild traumatic brain injury prescribed pre-injury antiplatelet medications. Neurocrit Care. https://doi.org/ 10.1007/s12028-019-00899-x

3. Batchelor JS, Grayson A (2013) A meta-analysis to determine the effect of preinjury antiplatelet agents on mortality in patients with blunt head trauma. Br J Neurosurg 27:12-18. https://doi.org/10. 3109/02688697.2012.705361

4. Bonville DJ, Ata A, Jahraus CB, Arnold-Lloyd T, Salem L, Rosati C, Stain SC (2011) Impact of preinjury warfarin and antiplatelet agents on outcomes of trauma patients. Surgery 150:861-868. https://doi.org/10.1016/j.surg.2011.07.070

5. Burger W, Chemnitius JM, Kneissl GD, Rücker G (2005) Lowdose aspirin for secondary cardiovascular prevention - cardiovascular risks after its perioperative withdrawal versus bleeding risks with its continuation - review and meta-analysis. J Intern Med 257: 399-414. https://doi.org/10.1111/j.1365-2796.2005.01477.x

6. Dossett LA, Riesel JN, Griffin MR, Cotton BA (2011) Prevalence and implications of preinjury warfarin use: an analysis of the National Trauma Databank. Arch Surg (Chicago, Ill : 1960) 146: 565-570. https://doi.org/10.1001/archsurg.2010.313

7. Dunham CM, Hoffman DA, Huang GS, Omert LA, Gemmel DJ, Merrell R (2014) Traumatic intracranial hemorrhage correlates with preinjury brain atrophy, but not with antithrombotic agent use: a retrospective study. PLoS One 9:e109473. https://doi.org/10.1371/ journal.pone. 0109473

8. Effects of tranexamic acid on death, disability, vascular occlusive events and other morbidities in patients with acute traumatic brain injury (CRASH-3): a randomised, placebo-controlled trial Lancet, 394(2019):1713-1723. https://doi.org/10.1016/s0140-6736(19)322330

9. Elf K, Nilsson P, Enblad P (2002) Outcome after traumatic brain injury improved by an organized secondary insult program and standardized neurointensive care. Crit Care Med 30:2129-2134. https://doi.org/10.1097/01.Ccm.0000025893.73582.52

10. Fabbri A, Servadei F, Marchesini G, Bronzoni C, Montesi D, Arietta L (2013) Antiplatelet therapy and the outcome of subjects with intracranial injury: the Italian SIMEU study. Crit Care (London, England) 17:R53. https://doi.org/10.1186/cc12575

11. Franko J, Kish KJ, O'Connell BG, Subramanian S, Yuschak JV (2006) Advanced age and preinjury warfarin anticoagulation increase the risk of mortality after head trauma. J Trauma 61:107110. https://doi.org/10.1097/01.ta.0000224220.89528.fc

12. Frontera JA, Lewin JJ 3rd, Rabinstein AA, Aisiku IP, Alexandrov AW, Cook AM, Del Zoppo GJ, Kumar M, Peerschke EI, Stiefel MF, Teitelbaum JS, Wartenberg KE, Zerfoss CL (2016) Guideline for reversal of antithrombotics in intracranial hemorrhage: executive summary. A statement for healthcare professionals from the Neurocritical Care Society and the Society of Critical Care Medicine. Crit Care Med 44:2251-2257. https://doi.org/10.1097/ ccm.0000000000002057

13. Ganetsky M, Lopez G, Coreanu T, Novack V, Horng S, Shapiro NI, Bauer KA (2017) Risk of Intracranial hemorrhage in ground-level fall with antiplatelet or anticoagulant agents. Acad Emerg Med 24: 1258-1266. https://doi.org/10.1111/acem.13217

14. Grandhi R, Harrison G, Voronovich Z, Bauer J, Chen SH, Nicholas D, Alarcon LH, Okonkwo DO (2015) Preinjury warfarin, but not antiplatelet medications, increases mortality in elderly traumatic brain injury patients. J Trauma Acute Care Surg 78:614-621. https://doi.org/10.1097/ta.0000000000000542

15. Ivascu FA, Howells GA, Junn FS, Bair HA, Bendick PJ, Janczyk RJ (2005) Rapid warfarin reversal in anticoagulated patients with traumatic intracranial hemorrhage reduces hemorrhage progression and mortality. J Trauma 59:1131-1137; discussion 1137-1139. https://doi.org/10.1097/01.ta.0000189067.16368.83 
16. Joseph B, Pandit V, Aziz H, Kulvatunyou N, Hashmi A, Tang A, O'Keeffe T, Wynne J, Vercruysse G, Friese RS, Rhee P (2014) Clinical outcomes in traumatic brain injury patients on preinjury clopidogrel: a prospective analysis. J Trauma Acute Care Surg 76: 817-820. https://doi.org/10.1097/TA.0b013e3182aafcf0

17. Kothari RU, Brott T, Broderick JP, Barsan WG, Sauerbeck LR, Zuccarello M, Khoury J (1996) The ABCs of measuring intracerebral hemorrhage volumes. Stroke 27:1304-1305. https://doi.org/10. 1161/01.str.27.8.1304

18. Lenell S, Nyholm L, Lewen A, Enblad P (2019) Clinical outcome and prognostic factors in elderly traumatic brain injury patients receiving neurointensive care. Acta Neurochir 161:1243-1254. https://doi.org/10.1007/s00701-019-03893-6

19. Lenell S, Nyholm L, Lewén A, Enblad P (2015) Updated periodic evaluation of standardized neurointensive care shows that it is possible to maintain a high level of favorable outcome even with increasing mean age. Acta Neurochir 157:417-425. https://doi.org/ 10.1007/s00701-014-2329-9

20. Maegele M, Schochl H, Menovsky T, Marechal H, Marklund N, Buki A, Stanworth S (2017) Coagulopathy and haemorrhagic progression in traumatic brain injury: advances in mechanisms, diagnosis, and management. Lancet Neurol 16:630-647. https://doi.org/ 10.1016/s1474-4422(17)30197-7

21. Marshall LF, Marshall SB, Klauber MR, van Berkum CM, Eisenberg HM, Jane JA, Luerssen TG, Marmarou A, Foulkes MAJ (1991) A new classification of head injury based on computerized tomography. J Neurosurg 75:S14-S20

22. Mathieu F, Güting H, Gravesteijn B, Monteiro M, Glocker B, Kornaropoulos EN, Kamnistas K, Robertson CS, Levin H, Whitehouse DP, Das T, Lingsma HF, Maegele M, Newcombe VFJ, Menon DK (2020) Impact of antithrombotic agents on radiological lesion progression in acute traumatic brain injury: a CENTER-TBI Propensity-Matched Cohort Analysis. J Neurotrauma. https://doi.org/10.1089/neu.2019.6911

23. Mina AA, Knipfer JF, Park DY, Bair HA, Howells GA, Bendick PJ (2002) Intracranial complications of preinjury anticoagulation in trauma patients with head injury. J Trauma 53:668-672. https:// doi.org/10.1097/00005373-200210000-00008

24. Nyholm L, Howells T, Enblad P, Lewén A (2013) Introduction of the Uppsala Traumatic Brain Injury register for regular surveillance of patient characteristics and neurointensive care management including secondary insult quantification and clinical outcome. Ups J Med Sci 118:169-180. https://doi.org/10.3109/03009734.2013.806616

25. Otley CC (2003) Continuation of medically necessary aspirin and warfarin during cutaneous surgery. Mayo Clin Proc 78:1392-1396. https://doi.org/10.4065/78.11.1392

26. Powers AY, Pinto MB, Aldridge AM, Tang OY, Chen JS, Berube RL, Doberstein C, Fox JM, Carnevale JA, Asaad WF (2018) Factors associated with the progression of conservatively managed acute traumatic subdural hemorrhage. J Crit Care 48:243-250. https://doi.org/10.1016/j.jcrc.2018.09.014

27. Rowell SE, Meier EN, McKnight B, Kannas D, May S, Sheehan K, Bulger EM, Idris AH, Christenson J, Morrison LJ, Frascone RJ, Bosarge PL, Colella MR, Johannigman J, Cotton BA, Callum J, McMullan J, Dries DJ, Tibbs B, Richmond NJ, Weisfeldt ML, Tallon JM, Garrett JS, Zielinski MD, Aufderheide TP, Gandhi RR, Schlamp R, Robinson BRH, Jui J, Klein L, Rizoli S, Gamber M, Fleming M, Hwang J, Vincent LE, Williams C, Hendrickson A, Simonson R, Klotz P, Sopko G, Witham W, Ferrara M, Schreiber MA (2020) Effect of out-of-hospital tranexamic acid vs placebo on 6-month functional neurologic outcomes in patients with moderate or severe traumatic brain injury. JAMA 324:961-974. https:/doi. org/10.1001/jama.2020.8958
28. Scotti P, Seguin C, Lo BWY, de Guise E, Troquet JM, Marcoux J (2019) Antithrombotic agents and traumatic brain injury in the elderly population: hemorrhage patterns and outcomes. J Neurosurg: 1-10. https://doi.org/10.3171/2019.4.Jns19252

29. Shin SS, Marsh EB, Ali H, Nyquist PA, Hanley DF, Ziai WC (2020) Comparison of traumatic intracranial hemorrhage expansion and outcomes among patients on direct oral anticoagulants versus vitamin K antagonists. Neurocrit Care 32:407-418. https://doi.org/ 10.1007/s12028-019-00898-y

30. Steyerberg EW, Mushkudiani N, Perel P, Butcher I, Lu J, McHugh GS, Murray GD, Marmarou A, Roberts I, Habbema JD, Maas AI (2008) Predicting outcome after traumatic brain injury: development and international validation of prognostic scores based on admission characteristics. PLoS Med:5. https://doi.org/10.1371/ journal.pmed.0050165

31. Steyerberg EW, Wiegers E, Sewalt C, Buki A, Citerio G, De Keyser V, Ercole A, Kunzmann K, Lanyon L, Lecky F, Lingsma H, Manley G, Nelson D, Peul W, Stocchetti N, von Steinbuchel N, Vande Vyvere T, Verheyden J, Wilson L, Maas AIR, Menon DK (2019) Case-mix, care pathways, and outcomes in patients with traumatic brain injury in CENTER-TBI: a European prospective, multicentre, longitudinal, cohort study. Lancet Neurol 18:923-934. https://doi.org/10.1016/s1474-4422(19)30232-7

32. Stocchetti N, Paternò R, Citerio G, Beretta L, Colombo A (2012) Traumatic brain injury in an aging population. J Neurotrauma 29: 1119-1125. https://doi.org/10.1089/neu.2011.1995

33. Sumiyoshi K, Hayakawa T, Yatsushige H, Shigeta K, Momose T, Enomoto M, Sato S, Takasato Y (2017) Outcome of traumatic brain injury in patients on antiplatelet agents: a retrospective 20 -year observational study in a single neurosurgery unit. Brain Inj 31: 1445-1454. https://doi.org/10.1080/02699052.2017.1377349

34. Sundararajan V, Henderson T, Perry C, Muggivan A, Quan H, Ghali WA (2004) New ICD-10 version of the Charlson comorbidity index predicted in-hospital mortality. J Clin Epidemiol 57:12881294. https://doi.org/10.1016/j.jclinepi.2004.03.012

35. Teasdale GM, Pettigrew LE, Wilson JL, Murray G, Jennet B (1998) Analyzing outcome of treatment of severe head injury: a review and update on advancing the use of the Glasgow Outcome Scale. J Neurotrauma 15:587-597

36. Tollefsen MH, Vik A, Skandsen T, Sandrod O, Deane SF, Rao V, Moen KG (2018) Patients with moderate and severe traumatic brain injury: impact of preinjury platelet inhibitor or warfarin treatment. World Neurosurg 114:e209-e217. https://doi.org/10.1016/j.wneu.2018.02.167

37. Uccella L, Zoia C, Bongetta D, Gaetani P, Martig F, Candrian C, Rosso R (2018) Are antiplatelet and anticoagulants drugs a risk factor for bleeding in mild traumatic brain injury? World Neurosurg 110:e339-e345. https://doi.org/10.1016/j.wneu.2017.10.173

38. van den Brand CL, Tolido T, Rambach AH, Hunink MG, Patka P, Jellema K (2017) Systematic review and meta-analysis: is pre-injury antiplatelet therapy associated with traumatic intracranial hemorrhage? J Neurotrauma 34:1-7. https://doi.org/10.1089/neu.2015.4393

39. Wettervik TS, Lenell S, Nyholm L, Howells T, Lewen A, Enblad P (2018) Decompressive craniectomy in traumatic brain injury: usage and clinical outcome in a single centre. Acta Neurochir 160:229 237. https://doi.org/10.1007/s00701-017-3418-3

40. Wilson JL, Pettigrew LE, Teasdale GM (1998) Structured interviews for the Glasgow Outcome Scale and the extended Glasgow Outcome Scale: guidelines for their use. J Neurotrauma 15:573-585

Publisher's note Springer Nature remains neutral with regard to jurisdictional claims in published maps and institutional affiliations. 